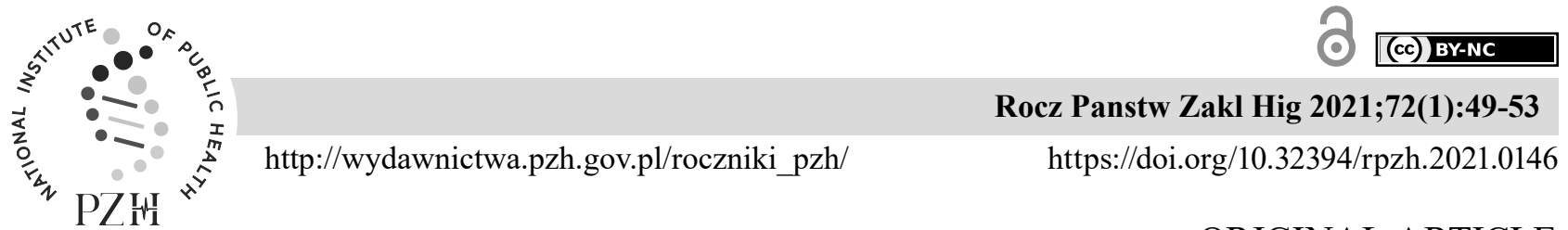

ORIGINAL ARTICLE

\title{
EXPOSURE ASSESSMENT OF BISPHENOL A BY DRINKING COFFEE FROM PLASTIC CUPS
}

\author{
Wael Mahmoud Hananeh ${ }^{1}$, Raida Al Rukibat ${ }^{1}$, Shefa Jaradat ${ }^{1}$, Mohammad Borhan Al-Zghoul ${ }^{2}$ \\ ${ }^{1}$ Department of Pathology and Public Health, Faculty of Veterinary Medicine, \\ Jordan University of Science and Technology, Irbid, Jordan \\ ${ }^{2}$ Department of Basic Medical Veterinary Sciences, Faculty of Veterinary Medicine, \\ Jordan University of Science and Technology, Irbid, Jordan
}

\begin{abstract}
Background. Human exposure to plastic and Bisphenol-A (BPA) is very wide in food or beverage containers and baby bottles that have contacted polycarbonate and epoxy resin. Currently a traditional beverage in Arabian culture is served in plastic cups instead of glass cups in different occasions

Objective. To evaluate the possible BPA leach from the grade 5 drinking coffee plastic cups into the coffee and whether the use of plastic cups instead of glass ones to serve hot Arabian coffee poses a health risk

Materials and methods. Oral administration of such coffee to three different groups of rats were undertaken. Each group consisted of 10 males and 10 females. The first group (G1) was gavaged $1.5 \mathrm{ml}$ of hot water in glass cups. The second group (G2) was gavaged $1.5 \mathrm{ml}$ of hot water in plastic cups while the third one (G3) was gavaged $1.5 \mathrm{ml}$ of Arabian coffee in plastic cups. Serum concentrations of Bisphenol-A were measured 4 weeks later. Complete postmortem examination was conducted and representative tissue samples were subjected to histopathological evaluation.

Results. In the control group receiving water kept in a glass cup had $24 \pm 2 \mu \mathrm{g} / \mathrm{L}$ serum concentration and the second group was $36 \pm 4 \mu \mathrm{g} / \mathrm{L}$ while in the third group was $29 \pm 6 \mu \mathrm{g} / \mathrm{L}$. No significant postmortem changes or histopathological findings were present in the studied animals.

Conclusions. Bisphenol-A can be leached from food-grade plastic cups into hot drinks within short period of time, posing a significant impact to public health.
\end{abstract}

Keywords: Arabian coffee, plastic, BPA, public health

\section{INTRODUCTION}

Bisphenol A (BPA) is a known endocrine disruptor that has been existing in our environment and it was first produced by A.P. Dianin in 1891 [18]. BPA is the common name for 2, 2-(4, 4'-dihydroxydiphenyl) propane, 4, 4'-isopropyllidenediphenol, alternatively 2 , 2 'bis (4-hydroxyphenyl) propane, an organic compound with two phenol moieties. The main properties of BPA is low vapor pressure, moderate water solubility, and low volatility and also solid at room temperature [9]. In the 1940s and 1950s, a use for BPA was identified in the plastics industry as a building block for polycarbonate plastic [18]. Also a component of epoxy resins is used for dental materials and in the lining of food and beverage containers [18]. About 95\% of BPA produced in industry is used to make polycarbonate and epoxy resins, with the remaining $5 \%$ used in a variety of products like drinking containers, plastic cups, eyeglasses, water pipes and medical equipment [9]. It had been shown that BPA was leached from food and beverage container, inhalation, house hold dust and dermal exposure [15].

In Jordanian culture, as part of their tradition and hospitality, Arabian coffee is served for the guests especially in big social events where large number of people attend. It is used to be served in small cups made of glass. Nowadays, serving Arabian coffee in plastic cups instead of glass ones becomes a famous phenomenon. Furthermore, coffee is a traditional beverage in Arabian culture that is served as a very hot drink.

Many researchers had studied the effect of the most important component in plastic, which is BPA and found that it has several negative impact on the human health $[11,7,4,10]$. People should think about this

Corresponding author: Wael Mahmoud Hananeh, Department of Pathology and Public Health, Faculty of Veterinary Medicine, Jordan University of Science and Technology, P. O. Box, 3030, Irbid 22110, Jordan, e-mail: whananeh@just.edu.jo

(C) Copyright by the National Institute of Public Health - National Institute of Hygiene 
material and its risk because plastic materials are wide industry and had been produced in huge quantities worldwide [12]. This study was done to determine the BPA concentration that might leach from the plastic cups to the coffee and subsequently its concentration in the blood using rat model. Furthermore, the clinical, hematological and histopathological changes were reported. No such study was conducted to explore such effects experimentally.

\section{MATERIALS AND METHODS}

\section{Animals}

The study protocol was reviewed and approved by the Institutional Animal Care and Use Committee (IACUC) of Jordan University of Science and Technology (JUST). Sixty western male and female rats weighing around 250 grams were used. The rats were housed in standard cages in the animal house at JUST. The rats were acclimatized to the working environment for one week before starting the experiment

\section{Experiment Design}

The rats were divided into three groups each group consist of 10 male and 10 females, group 1 (G1) was gavaged $1.5 \mathrm{ml}$ of hot water in glass cups, group 2 (G2) was gavaged $1.5 \mathrm{ml}$ of hot water in plastic cups and group 3 (G3) was gavaged $1.5 \mathrm{ml}$ of Arabian coffee in plastic cups.

The coffee preparation was done by dissolving 30 -gram coffee powder in $100 \mathrm{ml}$ distilled water and prepared daily then were poured into the cups. The coffee stayed in the plastic cups for 10 seconds and then transferred to glass cups to get cold in order to gavage it to the rats. The used plastic cups were of food grade plastic number 5 .

\section{Sampling}

At the end of the experiment, blood samples from different animal groups were collected in plane and EDTA tubes. Complete blood count (CBC) were determined for all collected samples. The sera were collected and kept in deep freeze $\left(-70{ }^{\circ} \mathrm{C}\right)$ for 4 weeks for BPA analysis. All rats were humanly killed according to the regulation of JUST- IACUC. Each rat was examined grossly. Liver and kidneys from each animal were weighed. Representative tissue sections from the lungs, hearts, livers, spleens, kidneys, adrenal glands gastrointestinal tracts and pancreases were taken and fixed in $10 \%$ formalin for 24 hours.

\section{Tissue fixation}

Fixed tissues were processed routinely in a histokinette processor then embedded into paraffin blocks. A $5 \mu \mathrm{m}$ thick section was made from each tissue and stained with Hematoxylin and Eosin stain (H\&E). The prepared slides were examined microscopically for any significant histopathological lesion.

\section{BPA ELISA}

Different concentrations of Rat BPA standard samples were added to corresponding wells ( $50 \mu \mathrm{l}$ for each well). The blanks were set separately. A $40 \mu \mathrm{l}$ of sample diluent was added to $10 \mu$ of testing sample (final dilution of the sample is 5 folds) then HRPconjugate reagent 100 testing sample were added to each well except the blank. The samples were incubated at $37{ }^{\circ} \mathrm{C}$ for $60 \mathrm{~min}$. ELISA plate was washed 5 time (20-fold wash solution diluted 20 -fold with distilled water) then biotinylated Rat BPA antibody liquid was added to each well (100 $\mu$ l for each). $50 \mu \mathrm{l}$ chromogen solution A $50 \mu 1$ and chromogen B were added to each well (also into blank well), Hatching in dark for 15 $\min$ at 37 . In order to stop the reaction, a $50 \mu 1$ of stop solution was added and mixed well. Absorbance was read at $450 \mathrm{~nm}$ within $10 \mathrm{~min}$ using Biotek PowerWave XS2 Spectrophotometer (Bio Tek Instruments, Inc., USA). The test was repeated twice to ensure that the reported results were consistent each time.

\section{RESULTS}

During the entire experiment, all rats within the different groups survived until the end of the experiments. No clinical abnormalities were noted. Neither water consumption nor feed intake was affected in any group in the experiment. Moreover, no differences in either the total body weight or body organ weight were present between the different groups.

Complete blood count was determined in all samples and the results were summarized in Table 1. No significant differences were found between all groups $(\mathrm{P}<0.05)$. It's worth mentioning that the concentration of BPA was measured on coffee samples that were present in plastic cup and glass cup by ELISA prior to the administration to the animals. It was found that coffee in plastic cups contained $0.222 \mu \mathrm{g} / \mathrm{L}$ while those in glass contained $0.076 \mu \mathrm{g} / \mathrm{L}$ of BPA. Because of the small amount of BPA measured in the coffee samples in glass cups, the coffee was not considered as a potential source for BPA and hence a $4^{\text {th }}$ group receiving coffee in glass cups was considered as redundant. 
Table 1. Complete blood count for tested samples G1, G2 and G3. The results are presented as mean \pm SD

\begin{tabular}{|c|c|c|c|}
\hline & G1 & G2 & G3 \\
\hline $\mathrm{WBC} \times 10^{3} / \mu \mathrm{l}$ & $9.23 \pm 1.77$ & $8.90 \pm 2.11$ & $10.375 \pm 2.72$ \\
\hline $\mathrm{RBC} \times 10^{6} / \mu \mathrm{l}$ & $8.09 \pm 0.48$ & $8.32 \pm 0.92$ & $8.382 \pm 0.5$ \\
\hline $\mathrm{HB} \mathrm{g} / \mathrm{dl}$ & $15.78 \pm 0.7$ & $16.42 \pm 1.3$ & $16.04 \pm 0.76$ \\
\hline $\mathrm{HCT} \%$ & $43.4 \pm 1.89$ & $45.32 \pm 3.13$ & $44.69 \pm 2.22$ \\
\hline $\mathrm{MCV} \mathrm{fl}$ & $53.19 \pm 1.89$ & $54.93 \pm 1.89$ & $53.37 \pm 1.76$ \\
\hline $\mathrm{MCH} \mathrm{Pg}$ & $19.53 \pm 0.75$ & $19.81 \pm 1.09$ & $19.171 \pm 0.76$ \\
\hline $\mathrm{MCHC} \mathrm{g/dl}$ & $36.74 \pm 0.65$ & $36.42 \pm 0.79$ & $35.911 \pm 0.50$ \\
\hline $\mathrm{PLT} \times 10^{3} / \mu \mathrm{l}$ & $891.73 \pm 64.69$ & $856.62 \pm 63.26$ & $877.45 \pm 71.92$ \\
\hline
\end{tabular}

G1 - hot water in glass cups, G2 - hot water in plastic cups, G3 - coffee in plastic cups

Postmortem examinations revealed no significant differences between different groups. Morphologically, different organ systems in the entire groups failed to express any significant gross changes. The histopathological examinations of liver, kidneys, lungs, pancreas, intestines, adrenals and brain showed no significant histopathological findings between different groups. All examined tissue sections were within normal limits.

Serum samples from different groups were analyzed for the presence of BPA using ELISA. It was found that the concentration of serum BPA in the treatment groups was significantly higher that their normal counterparts. Table 2 represents the mean $\pm \mathrm{SD}$ of BPA serum concentrations treatment and control groups.

Table 2. Serum BPA concentration of rats in tested samples $\mathrm{G} 1, \mathrm{G} 2$ and $\mathrm{G} 3$. The results are presented as mean $\pm \mathrm{SD}$ (in $\mu \mathrm{g} / \mathrm{L})$

\begin{tabular}{|c|c|c|}
\hline $\begin{array}{c}\mathrm{G} 1 \\
(\mu \mathrm{g} / \mathrm{L})\end{array}$ & $\begin{array}{c}\mathrm{G} 2 \\
(\mu \mathrm{g} / \mathrm{L})\end{array}$ & $\begin{array}{c}\mathrm{G} 3 \\
(\mu \mathrm{g} / \mathrm{L})\end{array}$ \\
\hline $23.88 \pm 1.92^{\mathrm{a}}$ & $36.99 \pm 2.39^{\mathrm{bc}}$ & $28.65 \pm 2.08^{\mathrm{b}}$ \\
\hline
\end{tabular}

${ }^{\mathrm{a}-\mathrm{c}}$ within the same row,

means $\pm \mathrm{SD}$ with different superscript are significantly different ( $p$-value < 0.05), G1 - hot water in glass cups, G2 - hot water in plastic cups, G3 - coffee in plastic cups

\section{DISCUSSION}

In our daily life, we are exposed to plastic through food or beverage containers that have contacted with polycarbonate and epoxy resin. Once the foodstuffs contacted the internal plastic surfaces, different chemical substances, including BPA, might migrate from plastic constiutents into the food and subsequently into our bodies [3]. This study was undertaken because a famous phenomenon was noticed in Jordan which was drinking Arabian coffee in disposable plastic cups instead of glass ones. Moreover, Arabian coffee is a traditional beverage in Arabian culture. It is served in big occasions and hence large numbers of people is exposed to possible health risks of such drift from glass to plastic, this study was conducted to measure the BPA concentration that migrated from plastic cups to the hot drinks and subsequently to our bodies.

In 1988, the Society of the Plastics Industry (SPI) for proper recycling and disposing established a classification system for different types of plastic [13]. A code system was generated according to their properties, usage and safety. Presence of an SPI number on the bottom of the package indicates only that the package is manufactured from a certain resin type. In the current study the plastic cups were marked with an SPI code of 5 indicating that they are made of polypropylene (PP). Its resistance to heat and chemicals characterizes this type of plastic. In this study, it was found that the concentration of BPA in Arabian coffee that was poured in the plastic cups prior to the administration to the animals was $0.222 \mu \mathrm{g} / \mathrm{L}$ while those in glass cups contained $0.076 \mu \mathrm{g} / \mathrm{L}$ of BPA. The results indicated that the plastic cups used despite of its SPI code of 5 could not withstand heat and BPA was migrated from these cups to their content within short period of time. The amounts of BPA migration depend significantly on temperature and time $[8,5]$. It was reported that plastics identified by codes $1,2,4$ and 5 do not use BPA in their manufacturing process and these codes were considered as a safest choice for food use[20]. However, in this study BPA was leached from the plastic cups to their content. This result indicated that SPI cod 5 in those plastic cups contained BPA in their manufacturing processes and should not be rendered for hot beverage usage or considered as a safe alternative for glass cups. In human, the main routs of BPA exposure are ingestions, inhalation and skin absorption [19]. Furthermore, after 90 days of the conducted experiment, it was found that the serum concentration of BPA in hot Arabic coffee or water poured in plastic cups groups were significantly higher than the control groups. This result confirmed that BPA was leached from the examined plastic cups and was reached to the animal's circulations. In another study conducted by Kubwabo et al. [12], it was found that BPA was migrated from plastic baby bottle into water when exposed to different temperatures due to the hydrolysis of plastic bottles polymer by hot water aging. The authors found that BPA concentration were $0.12 \mu \mathrm{g} / \mathrm{L}$ at $40{ }^{\circ} \mathrm{C}$ and $1.77 \mu \mathrm{g} / \mathrm{L}$ at $60{ }^{\circ} \mathrm{C}$. Moreover, when the baby bottles filled with water and heated to $100{ }^{\circ} \mathrm{C}$ during three microwave cycles, it was found that the concentration of BPA in water was ranged from 0.7 to $50.1 \mu \mathrm{g} / \mathrm{L}$ [12].

The concentrations of serum BPA were speculated to be lower than the measured ones. In this study, the control group had a considerable amount of serum 
BPA $(24 \pm 2 \mu \mathrm{g} / \mathrm{L})$ despite the negligible amount of BPA $(0.08 \mu \mathrm{g} / \mathrm{L})$ in water that was gavaged to the rats. It is believed that the source of serum BPA was due to contamination since serum BPA was not determined directly. That contamination might happen after sera collection during storage. The serum samples were kept in plastic tubes for a month in deep freeze. It had been documented that leaching of Bisphenol-A from plastic storage containers with a leaching rate 40 -fold higher into sheep plasma as compared to water [16]. The same authors suggested that suggested that BPA might be highly soluble in body fluid more than that of water [16].

In this study, the concentration of BPA in the serum of rats receiving hot water versus coffee both from plastic cups varied significantly. The concentration of BPA in the serum of rats receiving hot water in plastic cups $(36 \pm 4 \mu \mathrm{g} / \mathrm{L})$ was significantly higher than those received coffee in plastic cups $(29 \pm 6 \mu \mathrm{g} / \mathrm{L})$. This difference could be attributed to the diuretic effect of the coffee since some of the BPA is excreated in urine. In rats, it was found that $6-8 \%$ of the administered BPA was recovered in urine [14].

The histopathological studies considered as very important indication for different pollutants effect and health status of population. Meanwhile, the current study showed no histopathological changes within the examined tissue related to BPA. No significant difference was seen between different groups. Similar results were obtained after 90-day and long-term oral studies in rats and mice. In those studies, noobserved-adverse-effect level of $25 \mathrm{mg} / \mathrm{kg}$ bw/day was reported related to Bisphenol-A administration [17]. In human, it was reported that BPA did not pose any health risk to differet age groups including eldery and prenatal when they exposed to BPA at $4 \mu \mathrm{g} / \mathrm{kg}$ bw/day level of exposure [2]. In contrary to this study, severe vacuolization in glomerular capillary with necrosis in the epithelial cells linings of the glomeruli and renal tubule in BPA treated groups in comparison with their control counterparts were reported $[1,6]$.

\section{CONCLUSIONS}

In conclusion, BPA could be found in food graded plastic and could not withstand the heat and as a result BPA could leach from the plastic into its content and consequently to the body. Furthermore, despite of lack of histological changes in the examined animals, that will not negate the impact of BPA in the body. This study showed that plastic poses a public health risk; therefore, a special consideration must be taken to minimize or prevent drinking hot beverages in plastic cup. Further studies are needed to investigate the effect of BPA on public health.

\section{Funding statement}

This work was supported by the Deanship of Research at Jordan University of Science and Technology. (Project No. 502/2015)

\section{Competing interest statement}

The authors declare no conflict of interest.

\section{Acknowledgments}

The authors would thank the Deanship of Research at JUST for their financial support.

\section{REFERENCES}

1. Adel J.H.: Histopathological study of lung, kidney, spleen and prostate in adult male rats treated with bisphenol A. Bas J Vet 2015; 14: 74-86.

2. Ćwiek-Ludwicka K: Bisphenol A (BPA) in food contact materials - new scientific opinion from EFSA regarding public health risk. Rocz Panstw Zakl Hig. 2015;66(4):299-307. PMID: 26656411.

3. Cwiek-Ludwicka K., Ludwicki J.K.: Endocrine disruptors in food contact materials; is there a health threat? Rocz Panstw Zakl Hig. 2014;65(3):169-77. PMID: 25247795.

4. Eladak S.,Grisin T., Moison D., Guerquin M., N'TumbaByn T., Pozzi-Gaudin S., Benachi A., Livera G., Rouiller-Fabre V., Habert R.: A new chapter in the bisphenol A story: bisphenol S and bisphenol F are not safe alternatives to this compound. Fertil Steril 2015; 103: 11-21.

5. Errico S., Bianco M., Mita L., Migliaccio M., Rossi S., Nicolucci C., Menale C., Portaccio M., Gallo P., Mita $D$. Migration of bisphenol A into canned tomatoes produced in Italy: dependence on temperature and storage conditions. Food Chem 2014; 160: 157-64.

6. Faheem M., Jahan N., Lone K.P.: Histopathological effects of bisphenol-A on liver, kidneys and gills of Indian major carp, Catla catla (Hamilton, 1822)', J Anim Plant Sci 2016; 26: 514-22.

7. Goldinger D.M., Demierre A., Zoller O., Rupp H., Reinhard H., Magnin R., Becker T.W., Bourqui-Pittet $M$. Endocrine activity of alternatives to BPA found in thermal paper in Switzerland. Regul Toxicol Pharmacol 2015; 71: 453-62.

8. Hahladakis J.N., Velis C.A., Weber R., Iacovidou E., Purnell P.: An overview of chemical additives present in plastics: migration, release, fate and environmental impact during their use, disposal and recycling. J Hazard Mater 2018; 344: 179-99.

9. Huang Y.Q., Wong C.C., Zheng J.S., Bouwman H., Barra R., Wahlström B., Neretin L., Wong M.: Bisphenol A (BPA) in China: a review of sources, environmental levels, and potential human health impacts. Environ Int 2012; 42: 91-99.

10. Kolatorova L., Duskova M., Vitku J., Starka L. Prenatal exposure to bisphenols and parabens and impacts on human physiology. Physiol Res 2017; 66:305-315. 
11. Korkmaz A., Ahbab M.A., Kolankaya D., Barlas N.: Influence of vitamin $\mathrm{C}$ on bisphenol $\mathrm{A}$, nonylphenol and octylphenol induced oxidative damages in liver of male rats. Food Chem Toxicol 2010; 48: 2865-71.

12.Kubwabo C., Kosarac I., Stewart B., Gauthier B.R., Lalonde K., Lalonde P.J.: Migration of bisphenol A from plastic baby bottles, baby bottle liners and reusable polycarbonate drinking bottles. Food Addit Contam Part B 2009; 26: 928-37.

13.Kumari N.A., Kumari P., Murthy N.S.: A Novel Mathematical Approach for Optimization of Plastic Degradation. IJETT 2013;4: 3539-42.

14. Kurebayashi H., Betsui H., Ohno Y.: Disposition of a low dose of 14C-Bisphenol A in male rats and its main biliary excretion as BPA glucuronide. Toxicol. Sci. 2003; 73, 17-25. doi: 10.1093/toxsci/kfg040.

15. Rochester J.R.: Bisphenol A and human health: a review of the literature. Reprod Toxicol 2013; 42: 132-55.

16. Sajiki J., Takahashi K., Yonekubo J.: Sensitive method for the determination of bisphenol-A in serum using two systems of high-performance liquid chromatography. J Chromatogr B Biomed Sci Appl 1999; 736: 255-61.
17. Scientific Committee for Food:: Certain monomers and other starting substances to be used in the manufacture of plastic materials and articles intended to come into contact with foodstuffs. Reports of the Scientific Committee for Food, 1986; (Seventeenth Series), EUR 10778 EN, Commission of the European Communities, Luxembourg

18. Vandenberg L.N., Maffini M.V., Sonnenschein C., Rubin B.S., Soto A.M.: Bisphenol-A and the great divide: a review of controversies in the field of endocrine disruption. Endocr Rev 2009; 30: 75-95.

19. Wang Z., Liu H., Liu S.: Low-dose bisphenol A exposure: A seemingly instigating carcinogenic effect on breast cancer. Adv Sci 2016;4(2):1600248, doi: 10.1002/ advs.201600248.

20. Whitney E.N., Rolfes S.R.: Understanding nutrition. Cengage Learning, 2018, ISBN-13: 9781337392693.

Received: 09.11.2020

Accepted: 01.02.2021 